\title{
Corrosion inhibition of copper and its alloy MNZh5-1 by salts of succinic and alkenylsuccinic acids in chloride solution ${ }^{1}$
}

\author{
M.O. Agafonkina, (i) I.A. Kuznetsov, iD* Yu.I. Kuznetsov ${ }^{(i)}$ \\ and N.P. Andreeva \\ A.N. Frumkin Institute of Physical Chemistry and Electrochemistry, Russian Academy \\ of Sciences, Leninskii pr. 31, 119071 Moscow, Russian Federation \\ *E-mail: anarenen@gmail.com
}

\begin{abstract}
The adsorption, protective and passivating effect of sodium salts of succinic, itaconic and a blend of alkenylsuccinic acids (SKAP-25) on the oxidized surface of copper and copper-nickel alloy MNZh5-1 in neutral buffer and chloride solutions was studied. The adsorption of sodium succinate and itaconate is adequately described by the full Temkin isotherm equation with the value of the free energy of adsorption $\left(-\Delta G_{\mathrm{a}}^{0}\right)$ on oxidized copper at $E=0.0 \mathrm{~V}$ being 77.4 and $65.4 \mathrm{~kJ} / \mathrm{mol}$, respectively. The values of $\left(-\Delta G_{\mathrm{a}}^{0}\right)$ for these corrosion inhibitors on the preoxidized MNZh5-1 alloy electrode are 89.3 and $58.3 \mathrm{~kJ} / \mathrm{mol}$, respectively. Such values of $\left(-\Delta G_{\mathrm{a}}^{0}\right)$ suggest chemisorption interaction of these organic anions with the oxidized surface of copper and its alloy. Corrosion tests of copper and alloy MNZh5-1 in solutions for 7 days showed that a formulation of SKAP with the sodium salt of 2-mercaptobenzothiazole with a 7.1:1.0 mass ratio of the components was the best corrosion inhibitor.
\end{abstract}

Keywords: copper, MNZh5-1 alloy, dicarboxylates, adsorption, neutral chloride media, ellipsometry, Temkin isotherm.

Received: September 23, 2021. Published: November 17, 2021 doi: $\underline{10.17675 / 2305-6894-2021-10-4-14}$

\section{Introduction}

Copper and copper-based alloys are structural materials and are actively used in many industries. Due to its high thermal conductivity and electrical conductivity, copper is currently used in renewable energy systems. Copper alloys are widely used in jewelry, monuments, electrical products, and heat exchangers. Despite the relatively high corrosion resistance of copper in many environments, including humid atmospheres, it corrodes with a patina.

In this regard, the task of improving the protection of copper and its alloys against corrosion remains relevant. One simple and affordable way to protect metal from corrosion

\footnotetext{
${ }^{1}$ This work was carried out with financial support from the Russian Foundation for Basic Research (Grant No. 20-03-00101 "Adsorption of anions of dicarboxylic acids on copper and its alloys and their passivation in neutral solutions").
} 
is to introduce organic corrosion inhibitors (CI) into the environment in which it is located. For this purpose, substances of azoles class are often used, for example, 1,2,3-benzotriazole (BTA), 2-mercaptobenzothiazole (2-MBT) and others [1-10].

In addition to azoles and their derivatives, salts of carboxylic acids are widely known as CIs of copper and its alloys [11-14]. Compared to azoles, these compounds are cheaper and less environmentally hazardous.

Earlier we studied the adsorption and protective properties of a number of carboxylates [14] and showed that the most effective are sodium oleate and sodium oleoylsarcosinate. On oxidized copper at $E=0.0 \mathrm{~V}$ the values of their free energy of adsorption $\left(-\Delta G_{\mathrm{a}}^{0}\right)$ are 62 and $57 \mathrm{~kJ} / \mathrm{mol}$, respectively. At the same time, dicarboxylic acids and their salts are studied relatively poorly, although interest in them, as the CIs of various metals in neutral environments and in the protection against atmospheric corrosion periodically arises [13-16]. This is due to the assumption that in the presence of two reactive carboxyl groups in their molecules, the adsorption energy value of dicarboxylates may be higher than that of monocarboxylates. Consequently, they can show higher protective and passivating properties.

Dicarboxylates have been studied extensively for the protection of mild steel and much less frequently for other metals [12-21]. A. Mercer [22] showed that dicarboxylates can be more effective than alkyl monocarboxylates. However, later German researchers [18], studying the effect of mono- and dicarboxylates on the passivation of mild steel in a $0.01 \mathrm{M}$ solution of potassium nitrate at $\mathrm{pH} 7.50$, noticed that its transition into a passive state occurs after different times. Thus, in a solution of sodium sebacinate or its mixture with caprinate, the passive state is established after 10-15 min of immersion of the electrode in it. In a solution of azelate or its mixture with pelargonate, passivation of soft steel is achieved not earlier than $25 \mathrm{~min}$. According to the results of electrochemical impedance spectroscopy (EIS) measurements, the resistance of the $R_{\mathrm{ad}}$ adsorption layer for dicarboxylates is lower than for monocarboxylates, which is due to the lower adsorption capacity of dicarboxylates.

K. Aramaki [17] suggested that $\alpha, \omega$-dicarboxylates with carbon atoms in alkylene $n_{\mathrm{C}}=7$ and 8 , are adsorbed on the surface of iron oxide due to two carboxyl groups, thus forming a loop. This position is disadvantageous for the formation of a tightly packed layer, whereas monocarboxylates with their long alkyl can create it by placing their alkyls almost perpendicular to the surface during adsorption. As a result, such an adsorption layer acts as a barrier to aggressive components of the medium. Comparing the results of EIS measurements, one can conclude that the higher the $R_{\text {ad }}$ value, the denser the adsorption layer is packed.

The authors [19] studied not only dicarboxylates themselves, but also their mixtures with BTA on mild steel in $0.02 \mathrm{M} \mathrm{NaCl}$ aqueous solution. They found that nontoxic dicarboxylates with $n_{\mathrm{C}}<4$ spontaneously passivate soft steel in chloride solution. These CIs inhibit the anodic reaction but have little or no effect on the cathodic reaction. The effectiveness of such dicarboxylates $\left(n_{\mathrm{C}}>4\right)$ increases if their mixtures with BTA are used, 
e.g. a high degree of steel corrosion inhibition is observed for a mixture of sebacinate with BTA.

In our work we studied dicarboxylate salts which are derivatives of succinic acid: sodium itaconate contains $=\mathrm{CH}_{2}$-group and SKAP - relatively long hydrocarbon chains, also including one double bond $\left(n_{\mathrm{C}}=12-15\right)$. These substituents are not located between carboxy groups in the hydrocarbon chain, but are attached to one of their binding methyl groups.

Adsorption, passivation and protective properties of sodium succinate, sodium itaconate and sodium salts of acids contained in the product known as KAP-25 [24] were studied on copper and its alloy MNZh5-1 in a neutral chloride solution.

\section{Experimental}

Working electrodes are made of M1 copper and MNZh5-1 alloy, containing in \%: 90.693.7 Cu; 5.0-6.5 Ni+Co; 1.0-1.4 Fe; 0.3-0.8 Mn; $\leq 0.5 \mathrm{Zn} ; \leq 0.15 \mathrm{Si} ; \leq 0.1 \mathrm{Sn} ; \leq 0.04 \mathrm{P}$; $\leq 0.01 \mathrm{~S}[25]$.

We used in our research commercial compounds - succinic (CAS Number 110-15-6, Sigma Aldrich) and itaconic (CAS Number 97-65-4 Acros Organics) acids, and also KAP25 (TU 2499-080-05015207-2003 Antirust additive KAP-25 from May 20, 2003, OAO PO TOS).

Sodium salts of succinic and itaconic acids were prepared by the neutralization reaction with sodium hydroxide solution. The exact composition of the additive KAP-25 is unknown, so the amount of alkali needed to convert acids from its composition into salts was taken from the acid number listed in the product data sheet, namely $382 \mathrm{mg} / \mathrm{g} \mathrm{KOH}$. Because the exact composition of KAP-25 is unknown, the product obtained after its neutralization is referred to in the article as SKAP-25, and its concentration is given in $\mathrm{g} / \mathrm{L}$. The concentration of the substance in the working solution was $33.7 \mathrm{~g} / \mathrm{L}$. The $\mathrm{pH}$ values of SKAP-25 working solutions were maintained between 6.7 and 7.4.

For ellipsometric measurements, sodium succinate and itaconate solutions with the concentration $C_{\text {in }}=10^{-8}-10^{-10} \mathrm{M}$ were used; for electrochemical and corrosion studies, 0.05 and $0.1 \mathrm{M}$ concentrates were used.

Studies of adsorption on the oxidized surface of copper and alloy were carried out on a manually operated RR 2000 ellipsometer with an electrochemical cell, which simultaneously allows to maintain the electrode potential $E$ set from the potentiostat and measure the ellipsometric phase angle. The accuracy in determining the angle is $\pm 0.05^{\circ}$. Potentials of the electrode in solution, $E$, were measured relative to the silver chloride reference electrode; their values are given in the article in terms of a standard hydrogen electrode. The potential of the oxidized electrode surface for copper and alloy $E=0.0 \mathrm{~V}$ (SHE).

For a homogeneous film thickness $d \leq 10 \mathrm{~nm}$, the Drude equation is valid, which allows us to pass from changes to the degree of surface coverage [26]:

$$
d=-\alpha \delta \Delta=-\alpha\left(\Delta-\Delta_{0}\right)
$$


where $\alpha$ is a proportionality coefficient, $\Delta_{0}$ is the value of the angle for the initial surface, and $\Delta$ is the value of the angle during the experiment. If adsorption occurs, then $\delta \Delta=\left(\Delta-\Delta_{0}\right)<0$.

To obtain the isotherm of CI adsorption on the pre-oxidized electrode at $E=0.0 \mathrm{~V}$, its concentrate was added in portions to the cell with borate buffer solution $\mathrm{pH}$ 7.4. For each $C_{\text {in }}$, the angle $\Delta$ decreased in time and stopped changing after 60-90 min. Thus, we determine the angle difference $(-\delta \Delta)$ to plot its dependence on $C_{\text {in }}$. The value of Sin, at which the angle change stops, corresponds to a certain degree of coverage $\theta . C_{\text {in }}$, at which the value $(-\delta \Delta)$ stops changing, corresponds to the concentration of the formation of the first monolayer, i.e., $\theta \rightarrow 1[27,28]$. The experimental dependence of the angle $\Delta$ change on $\log C_{\text {in }}$ is reconstructed into the adsorption isotherm $\theta=f(\ln C)$ and the adsorption free energy $\left(-\Delta G_{\mathrm{a}}^{0}\right)$ is calculated.

The adsorption of these compounds is adequately described by the full Temkin equation:

$$
\theta=\frac{1}{f} \ln \frac{1+B_{\max } C}{1+B_{\min } C}
$$

where $f$ is the surface heterogeneity factor characterizing the change in the enthalpy of adsorption with surface coverage; $B_{\max }$ and $B_{\min }$ are the adsorption equilibrium constants corresponding to the highest and lowest values of adsorption energy. The value of $B$ is related to the free energy of adsorption $\left(-\Delta G_{\mathrm{a}}^{0}\right)$ by the relation:

$$
B_{\max ,(\min )}=\exp \left[\left(-\Delta G_{\mathrm{a}, \max (\min )}^{0}\right) / R T\right]
$$

When determining $\left(-\Delta G_{\mathrm{a}, \max }^{0}\right),\left(-\Delta G_{\mathrm{a}, \min }^{0}\right), f$-factor, $B_{\max }$, and $B_{\min }$, we used the technique described earlier in [29].

Electrochemical studies consisted in recording anodic polarization curves in borate buffer solution with the addition of $0.01 \mathrm{M} \mathrm{NaCl}$ and different concentrations of CI. They were obtained on electrodes made of copper and alloy MNZh5-1 in an electrochemical cell with separated electrode spaces on an IPC-PRO MF potentiostat (RF). The working electrode was preliminarily roughened on sandpaper of different grit 400-1000 and degreased with acetone.

After removal of air formed film of metal oxides on the alloy (by keeping the electrode for $15 \mathrm{~min}$ in borate buffer with $\mathrm{pH} 7.4$ and $0.01 \mathrm{M} \mathrm{NaCl}$ at $E=-0.60 \mathrm{~V}$ ) the potentiostat was turned off till establishment of free corrosion potential $E_{\text {cor }}$. After establishing a new value of $E_{\text {cor }}$ formed by adsorption of organic CI molecules introduced into the buffer solution on the electrode, the potentiostat was connected again and polarization curves were recorded at the rate of potential sweep of $0.2 \mathrm{mV} / \mathrm{s}$.

The potential of local metal depassivation by chlorides, $E_{\mathrm{pt}}$, was determined by a sharp increase in current on the polarization curve followed by visual identification of pitting on the surface of the electrode. The error in the measurement of $E_{\mathrm{pt}}$ is $0.01 \mathrm{~V}$. The protective effect of the copper and alloy local depassivation inhibitor was estimated by the magnitude 
of the increase in $E_{\mathrm{pt}}$ caused by its introduction into the background solution, i.e., $\Delta E=E_{\mathrm{pt}}^{\mathrm{in}}-E_{\mathrm{pt}}^{\mathrm{bg}}$.

Corrosion studies of copper and its alloy were carried out in distilled water containing $0.01 \mathrm{M} \mathrm{NaCl}$ or $3.5 \% \mathrm{NaCl}$ and different $C_{\text {in }}$. Metal plates of dimensions $50 \times 30 \times 3 \mathrm{~mm}$ were cleaned on abrasive paper of different grit (from 240 to 1000), degreased with acetone and weighed before the experiment. Accuracy of weighing was $\pm 0.0002 \mathrm{~g}$. Samples were then placed in chloride solutions with dicarboxylates of different $C_{\text {in }}$ at room temperature $t=(22 \pm 2)^{\circ} \mathrm{C}$ and natural aeration of the solution. After 7 days, the plates were removed, cleaned of corrosion products, and weighed again. According to the difference in mass of the plate before and after the test, the corrosion rates in the background $\left(K_{0}\right)$ and inhibited solution $\left(K_{\text {in }}\right)$ were calculated and the degree of protection of copper $Z$ was determined by the formula:

$$
Z=\frac{K_{0}-K_{\text {in }}}{K_{0}} \cdot 100 \%
$$

A mixture of these substances with concentrations of $0.2157 \mathrm{~g} / \mathrm{L}$ and $0.0302 \mathrm{~g} / \mathrm{L}$ was prepared for corrosion tests of copper with SKAP- 25 composition and MBT sodium salt, respectively.

\section{Results and Discussion}

The adsorption of sodium succinate on the pre-reduced $(E=-0.60 \mathrm{~V})$ and oxidized $(E=0.0 \mathrm{~V})$ copper surface was studied earlier in pure borate buffer at $\mathrm{pH} 7.4$ [30]. These studies were carried out by ellipsometric method, by obtaining the adsorption isotherm and from it determining the values $\left(-\Delta G_{\mathrm{a}}^{0}\right)$ and $f$, characterizing the adsorption capacity of compounds. Adsorption of sodium succinate on an oxidized copper surface occurs in the region of very low $C_{\mathrm{in}}$ and is described by Eq. (2) with the value $-\Delta G_{\mathrm{a}, \max }^{0}=77.4 \mathrm{~kJ} / \mathrm{mol}$, which is $30 \mathrm{~kJ} / \mathrm{mol}$ higher than for its lower homologue sodium malonate. It is interesting, that on the copper electrode free from oxide film at $E=-0.60 \mathrm{~V}$ the $\left(-\Delta G_{\mathrm{a}, \max }^{0}\right)$ values for these compounds are much less ( 53.1 and $38.3 \mathrm{~kJ} / \mathrm{mol}$ respectively) but succinate adsorption remains strong enough to consider its interaction with the surface as chemisorption. Indeed, polarization measurements on copper at a concentration of $3 \mathrm{mmol} / \mathrm{L}$ of the above sodium salts of dicarboxylic acids on anodic dissolution of the metal in borate buffer containing $0.01 \mathrm{M}$ aggressive $\mathrm{NaCl}$ showed that the protective capacity of succinate is higher than that of sodium malonate.

\section{Electrochemical studies}

Additions of sodium succinate to borate-chloride solution at $C_{\text {in }}=0.5 \mathrm{mmol} / \mathrm{L}$ reduce the current density of anodic passivation copper $i_{\mathrm{p}}$ and increase $E_{\mathrm{pt}}$ on $\mathrm{Cu}$ samples by almost $0.30 \mathrm{~V}$ [23]. However, increasing $C_{\text {in }}$ to $1.0 \mathrm{mmol} / \mathrm{L}$ increases the passivation current 
density $i_{\mathrm{p}}$, and further growth of $C_{\mathrm{in}}$ to $5.0 \mathrm{mmol} / \mathrm{L}$, although it improves the ability of sodium succinate to stabilize the passive copper state, but $i_{\mathrm{p}}$ reaches $120 \mu \mathrm{A} / \mathrm{cm}^{2}$, which indicates the formation of its anions soluble complexes with $\mathrm{Cu}(\mathrm{I})$, preventing passivation of the electrode.

Sodium itaconate behaves differently from succinate (Figure 1). At the content of $0.25 \mathrm{mmol} / \mathrm{L}$ of this $\mathrm{CI}$ in the working solution there is no suppression of the copper anodic dissolution peak and the $i_{\mathrm{p}}$ shifts to a more negative region. When $C_{\mathrm{in}}$ is increased to $2 \mathrm{mmol} / \mathrm{L}, E_{\mathrm{pt}}$ increases, but $i_{\mathrm{p}}$ also increases, from which it can be concluded that soluble complexes with $\mathrm{Cu}(\mathrm{I})$ are formed. A similar situation was observed when sodium succinate $C_{\text {in }}$ was increased, but up to $5 \mathrm{mmol} / \mathrm{L}$.

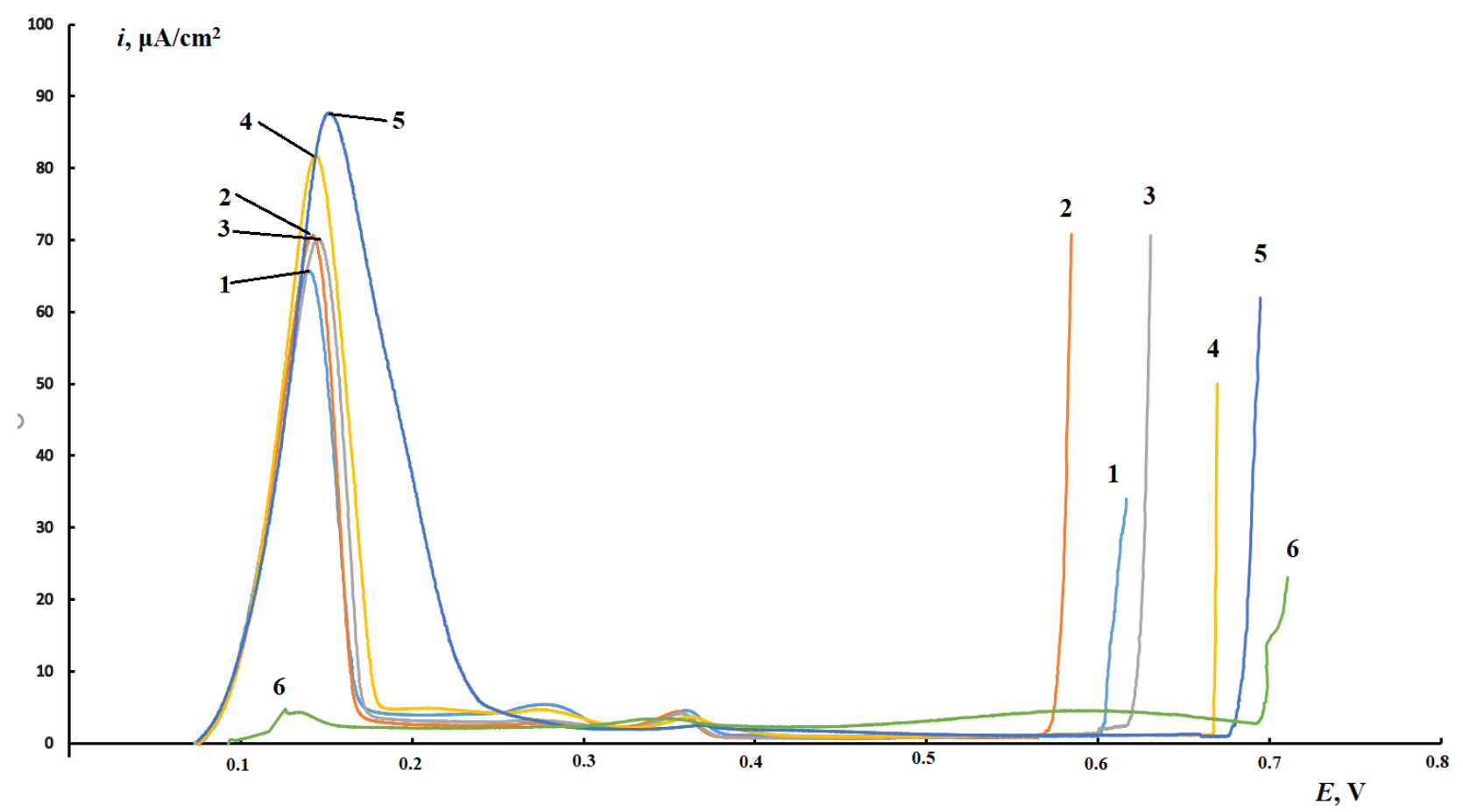

Figure 1. Anodic polarization curves of copper in borate buffer solution with $\mathrm{pH} 7.4$ containing $0.01 \mathrm{M} \mathrm{NaCl}$ without (1) and with addition of sodium itaconate (in $\mathrm{mmol} / \mathrm{L}$ ): 2 $0.25,3-0.5,4-1,5-2,6-5$.

However, further increase in the sodium itaconate $C_{\text {in }}$ leads to almost complete suppression of the anodic dissolution peak. At the same time, the free corrosion potential $E_{\text {cor }}$ and $E_{\mathrm{pt}}$ increase in comparison with $C_{\mathrm{in}}=2 \mathrm{mmol} / \mathrm{L}$. The difference in the behavior of sodium succinate and itaconate at the same $C_{\text {in }}$ can be explained by the presence of a methylene group and a double bond in the structure of the latter. Probably, the anion of itaconate under certain conditions is able, at least, to dimerize with breaking the double bond, which increases the hydrophobicity of this CI.

In contrast to copper, spontaneous passivation in the presence of sodium succinate occurs on alloy MNZh5-1 at $C_{\mathrm{in}}=0.25 \mathrm{mmol} / \mathrm{L}$, i.e. the first peak of $i_{\mathrm{p}}$ is suppressed and $E_{\mathrm{pt}}$ increases (Figure 2a). When $C_{\text {in }}$ increases up to $1.5 \mathrm{mmol} / \mathrm{L}$, the $E_{\mathrm{pt}}$ value increases, reaching 
$0.91 \mathrm{~V}$, but at $C_{\mathrm{in}}=2 \mathrm{mmol} / \mathrm{L}$ it decreases to $0.69 \mathrm{~V}$. It can be assumed that increasing $C_{\text {in }}$ succinate anions begin to form water-soluble complexes with metal cations included in the alloy, which weakens their ability to stabilize passivation of MNZh5-1. In this case, spontaneous passivation of the alloy is not disturbed and the second peak of the anodic current density only slightly increases, so we can assume that soluble complexes are not formed with $\mathrm{Cu}$ (II) cations. However, at $5 \mathrm{mmol} / \mathrm{L}$, unlike $2 \mathrm{mmol} / \mathrm{L}$, the $E_{\mathrm{pt}}$ does not decrease and the $i_{\mathrm{p}}$ of the first peak of anodic dissolution increases, which confirms the formation of succinate ion complexes with $\mathrm{Cu}(\mathrm{I})$.

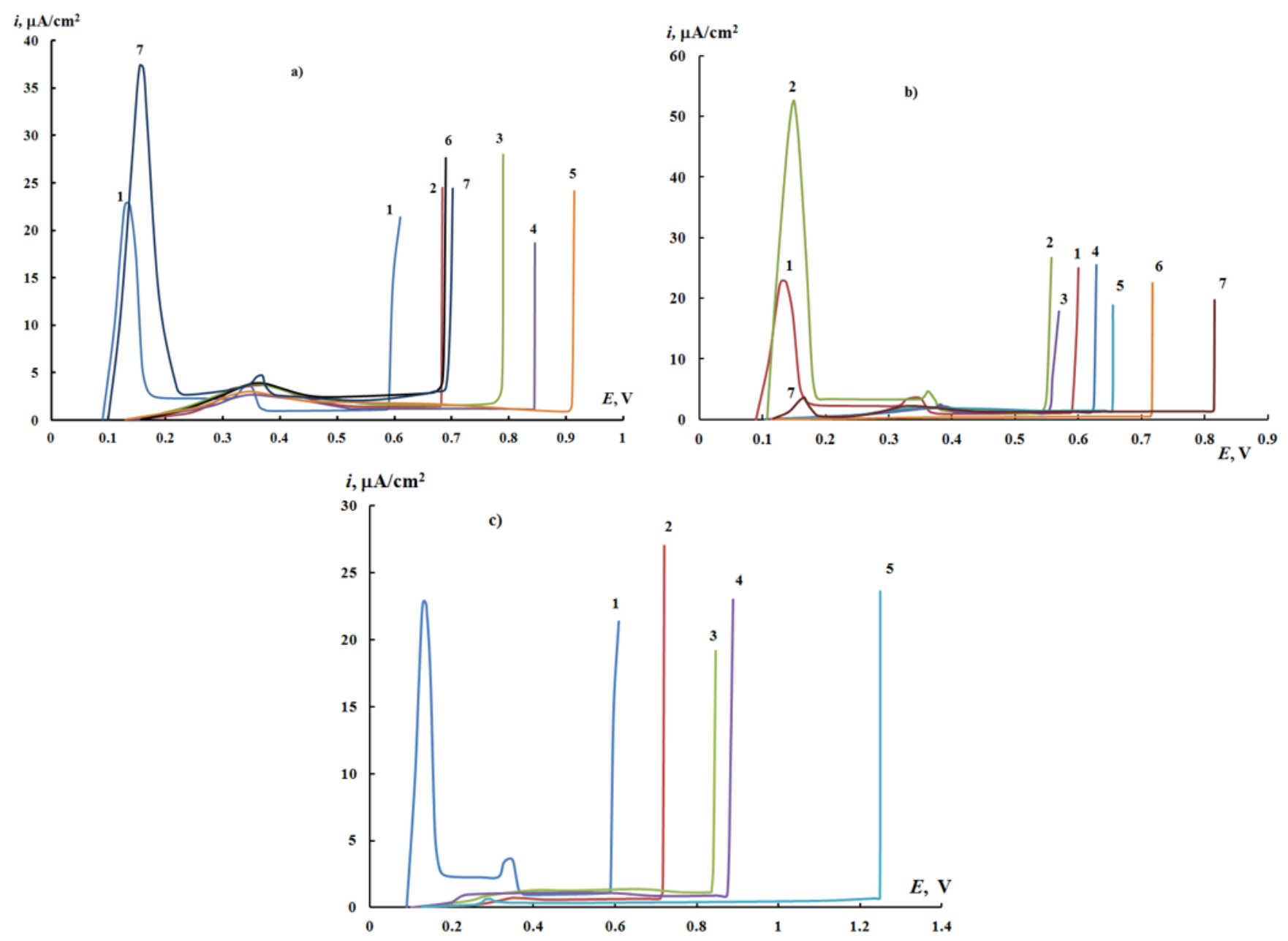

Figure 2. Anodic polarization curves of alloy MNZh5-1 in borate buffer solution of $\mathrm{pH} 7.4$ containing $0.01 \mathrm{M} \mathrm{NaCl}$ without (1) and with addition at $C_{\text {in }}(\mathrm{in} \mathrm{mmol} / \mathrm{L})$ a) sodium succinate: $2-0.25 ; 3-0.5 ; 4-1.0 ; 5-1.5 ; 6-2.0 ; 7-5$; b) Sodium itaconate: $2-0.13 ; 3-0.25$; $4-1.0 ; 5-1.5 ; 6-2.0 ; 7-5.0 ;$ c) $C_{\text {SKAP- } 25}(\mathrm{~g} / \mathrm{L}): 2-0.0843 ; 3-0.1685 ; 4-0.337$; $5-0.573$.

Sodium itaconate at low $C_{\text {in }}=0.13 \mathrm{mmol} / \mathrm{L}$ increases the $i_{\mathrm{p}}$ of the first peak by 2.5 times compared to the background curve without enrichment of $E_{\mathrm{pt}}$ (Figure 2b). Increasing to $C_{\text {in }}=0.25 \mathrm{mmol} / \mathrm{L}$ leads to spontaneous passivation of the electrode, but without increasing $E_{\mathrm{pt}}$. All subsequent studied $C_{\mathrm{in}}$ up to $5 \mathrm{mmol} / \mathrm{L}$ lead to an increase in $E_{\mathrm{pt}}$. For $C_{\mathrm{in}}=1 \mathrm{mmol} / \mathrm{L}$ 
the protective effect of $\Delta E=0.04 \mathrm{~V}$, and for $C_{\text {in }}=1.5$ and $5 \mathrm{mmol} / \mathrm{L} 0.07$ and $0.23 \mathrm{~V}$, respectively. Sodium itaconate in the region of concentrations $C_{\text {in }}=0.13-2 \mathrm{mmol} / \mathrm{L}$ suppresses the first and second peaks of anodic dissolution, but at $C_{\mathrm{in}}=5 \mathrm{mmol} / \mathrm{L}$ both peaks are present, similarly to what happens when sodium succinate is introduced at the same concentration. This fact again confirms that itaconium ions can also form water-soluble complexes with $\mathrm{Cu}(\mathrm{I})$ and $\mathrm{Cu}(\mathrm{II})$ cations when $C_{\text {in }}$ is increased.

According to [23], a mixture of substituted sodium alkenylsuccinate - SKAP-25 compounds at a concentration of $0.057 \mathrm{~g} / \mathrm{L}$ reduces the $i_{\mathrm{p}}$ of the first peak on copper by a factor of 10 and increases the $E_{\mathrm{pt}}$ to $0.76 \mathrm{~V}$. As SKAP- 25 increases up to $2.359 \mathrm{~g} / \mathrm{L}$, the $E_{\mathrm{pt}}$ increases and reaches the oxygen release potential $(E=1.2 \mathrm{~V})$. It is obvious that SKAP-25 is much more effective as an inhibitor of anodic dissolution of copper, succinate and itaconate sodium. This is due to the presence in its composition of hydrophobic anions with increased surface activity and their complex compounds with copper cations, if formed, are insoluble in aqueous solution. In this regard, we investigated the possibility of using SKAP-25 to protect the alloy MNZh5-1 in neutral solutions containing sodium chloride.

Anodic polarization curves of the MNZh5-1 alloy obtained in borate buffer containing $10 \mathrm{mmol} / \mathrm{L} \mathrm{NaCl}$ and SKAP-25 additives are shown in Figure 2c. All studied SKAP-25 additives suppress the first and second $i_{\mathrm{p}}$ peaks of the alloy and can increase the protective effect, which is expressed in the increase of $E_{\mathrm{pt}}$ of the sample. Thus, at $C_{\mathrm{SKAP}-25}=0.57 \mathrm{~g} / \mathrm{L}$ the passive state of the alloy is preserved in a wide range of potentials and the $E_{\mathrm{pt}}$ exceeds $1.25 \mathrm{~V}$, which on copper is achieved according to [23] at $C_{\text {in }}$ of this $\mathrm{CI}$ is 4 times higher.

\section{Ellipsometric studies}

Since spontaneous passivation of copper and alloy MNZh5-1 is caused by adsorption of dicarboxylic acid anions on their surface, its evaluation was carried out by ellipsometric method in pure borate buffer $\mathrm{pH} 7.4$ at constant $E=0.0 \mathrm{~V}$. In these experiments, the ellipsometric phase angle $\Delta$ stopped changing when the electrode was oxidized for 40 $50 \mathrm{~min}$. This allowed us to attribute the changes of $\Delta$ to the adsorption of dicarboxylate anions when injected into the solution of CI.

On the oxidized copper surface adsorption of sodium succinate $(\log D=-5.47)$, despite their high hydrophilicity (Table 1), occurs in the region of very low $C_{\text {in }}$ (Figure 3a). Apparently, this is due to the formation of a chelate complex with copper cations on the electrode surface. When the double bond is introduced into the sodium succinate structure, adsorption on oxidized copper also changes: sodium itaconate adsorbs at concentrations 2 orders of magnitude higher than sodium succinate. This is due to its higher hydrophilicity than succinate (Table 1).

The values $\left(-\Delta G_{\mathrm{a}, \max }^{0}\right)$ of the studied anions calculated by the full Temkin isotherm (Eq. 2) for sodium succinate and itaconate are 77.4 and $65.4 \mathrm{~kJ} / \mathrm{mol}$, respectively (Figure 3a, Table 2). The adsorption of sodium itaconate on copper starts from $C_{\text {in }}=0.1 \mathrm{nmol} / \mathrm{L}$ and reaches the limit of surface coverage when $C_{\mathrm{in}}=1 \mathrm{nmol} / \mathrm{L}$ is reached. The appearance of a 
multiple bond in the structure of sodium itaconate sharply reduces its adsorbability on the oxidized copper surface in neutral buffer solution as compared to succinate itself. This is explained by the increased hydrophilicity of the itaconate anion compared to succinate and its lower surface activity. In spite of this, itaconate chemisorbs on copper, although the surface complexes it forms are apparently less stable.

Table 1. Physicochemical characteristics of dicarboxylic acids: acid dissociation constants $\mathrm{p} K_{\mathrm{a}}, \log$ distribution coefficients $(\log P)$. Values of $\mathrm{p} K_{\mathrm{a}}, \log D$ and $\log P$ were obtained from chemicalize.com.

\begin{tabular}{cccc}
\hline Dicarboxylic acid & $\log \mathbf{P}$ & $\log \mathbf{D}$ & pKa \\
\hline $\begin{array}{c}\text { Succinic acid } \\
\mathrm{HOOC}-\left(\mathrm{CH}_{2}\right)_{2}-\mathrm{COOH}\end{array}$ & -0.40 & -5.47 & $3.55 ; 5.69$ \\
$\mathrm{KAP}-25^{*}$ & & & \\
$\mathrm{CH}_{3}\left(\mathrm{CH}_{2}\right)_{4} \mathrm{CH}=\mathrm{CH}\left(\mathrm{CH}_{2}\right)_{5}-$ & 4.23 & 4.36 & 4.82 \\
$\begin{array}{c}\mathrm{CHCH}_{2}(\mathrm{COOH})_{2} \\
\mathrm{CH}_{3}\left(\mathrm{CH}_{2}\right)_{5} \mathrm{CH}=\mathrm{CH}\left(\mathrm{CH}_{2}\right)_{7}-\end{array} \quad 4.39$ & 4.82 \\
$\begin{array}{c}\mathrm{CHCH} \\
\quad \text { Itaconic acid }\end{array}$ & 6.01 & -6.25 & $3.56 ; 4.37$ \\
$\left.\mathrm{HOOC}-\mathrm{CH}_{2}(\mathrm{C}=\mathrm{CH})_{2}\right) \mathrm{COOH}$ & 0.053 & & \\
\hline
\end{tabular}

*The main substances included in the KAP-25 are given.

Table 2. Adsorption characteristics of isotherms for sodium succinate and itaconate on the surface of copper and MNZh5-1 at the potential $E=0.0 \mathrm{~V}$ : minimum and maximum values of $B,-\Delta G_{\mathrm{a}}^{0}$, and factor $f$.

\begin{tabular}{|c|c|c|c|c|c|c|}
\hline Inhibitor & Metal & $\begin{array}{c}B_{\mathrm{i}, \max } \\
\mathbf{L} / \mathbf{m o l}\end{array}$ & $\begin{array}{c}B_{\mathrm{i}, \min } \\
\mathrm{L} / \mathrm{mol}\end{array}$ & $\begin{array}{c}-\Delta G_{\mathrm{a}, \min }^{0} \\
\mathbf{k J} / \mathbf{m o l}\end{array}$ & $\begin{array}{c}-\Delta G_{\mathrm{a}, \max }^{0} \\
\mathrm{~kJ} / \mathrm{mol}\end{array}$ & $f$ \\
\hline \multirow{2}{*}{$\begin{array}{l}\text { Sodium } \\
\text { succinate }\end{array}$} & Copper & $6.7 \cdot 10^{11}$ & $1.5 \cdot 10^{11}$ & 73.7 & 77.4 & 1.49 \\
\hline & MNZh5-1 & $8.3 \cdot 10^{13}$ & $2.3 \cdot 10^{13}$ & 86.1 & 89.3 & 1.26 \\
\hline \multirow{2}{*}{$\begin{array}{l}\text { Sodium } \\
\text { itaconate }\end{array}$} & Copper & $5.26 \cdot 10^{9}$ & $8.95 \cdot 10^{8}$ & 61.0 & 65.4 & 1.76 \\
\hline & MNZh5-1 & $3 \cdot 10^{8}$ & $7.2 \cdot 10^{7}$ & 54.7 & 58.3 & 1.43 \\
\hline
\end{tabular}

The adsorption of succinate anions on MNZh5-1 alloy begins at $C_{\text {in }} 2.5$ orders of magnitude lower than on copper (Figure 3b). It is adequately described by the equation of full Temkin isotherm with greater value $\left(-\Delta G_{\mathrm{a}, \max }^{0}\right)=89.3 \mathrm{~kJ} / \mathrm{mol}$ and smaller value $f=1.26$ than on copper (Table 2).

On the contrary, the adsorption of sodium itaconate on the oxidized alloy surface weakens, and the monolayer coverage of the surface occurs at $C_{\mathrm{in}}=10 \mathrm{nmol} / \mathrm{L}$. The value $\left(-\Delta G_{\mathrm{a}, \max }^{0}\right)$ calculated from Eq. (2) is $58.3 \mathrm{~kJ} / \mathrm{mol}$ (Table 2), which suggests its chemisorption, although weaker than that of succinate. The adsorption on the oxidized alloy 
in the case of sodium itaconate is characterized by a polylayer coverage of the surface shown by dashed lines in Figure 3b.

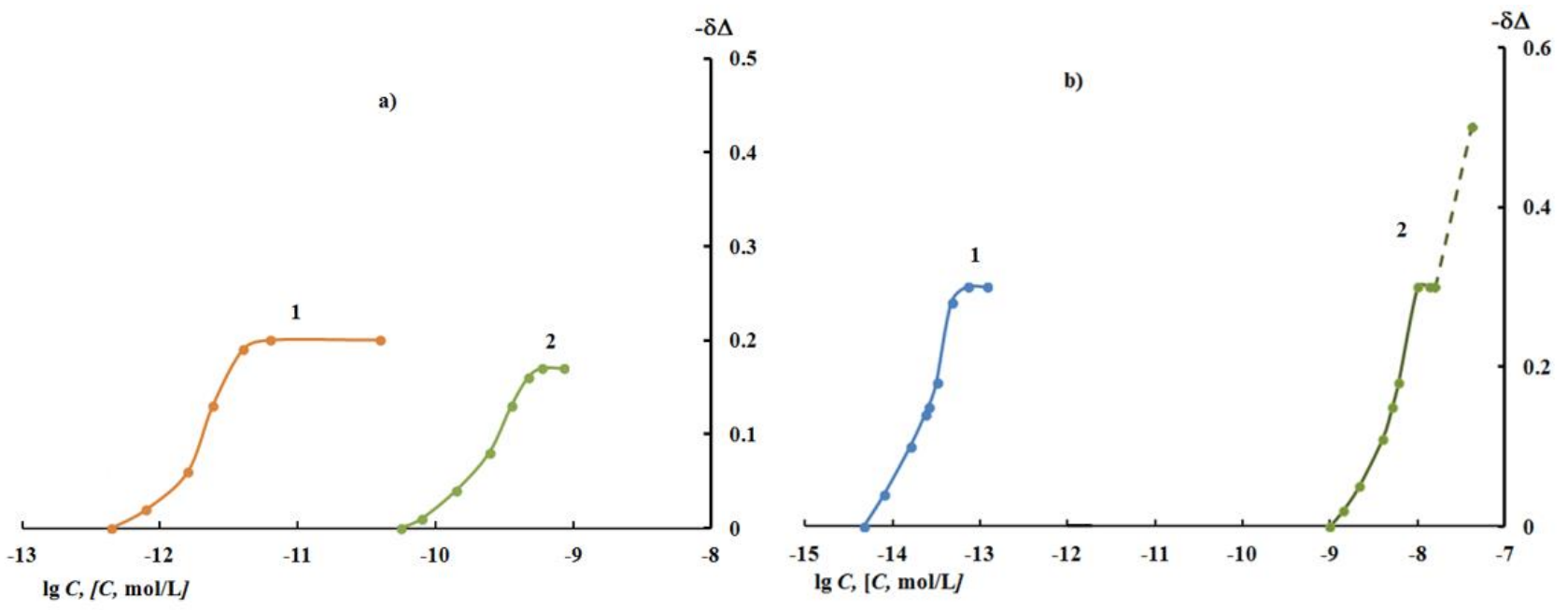

Figure 3. Dependence of the change in the ellipsometric angle $(-\delta \Delta)$ on the logarithm of the concentration of dicarboxylic acid anions in borate buffer solution with $\mathrm{pH}$ 7.4: (a) sodium succinate (1) and sodium itaconate (2) on an oxidized copper surface at $\mathrm{E}=0.0 \mathrm{~V}$ in borate buffer solution with $\mathrm{pH} 7$.

b) Sodium succinate (1), sodium itaconate (2) on the oxidized surface of the alloy MNZh5-1.

The dotted line shows the polymolecular adsorption

\section{Protective properties of the mixture of sodium salts KAP-25 and MBT}

Earlier in our works $[23,31]$ small additives of sodium salt of 2-mercaptobenzothiazole (SMBT) were used to enhance the protective effect of dicarboxylates. According to impedance measurements [23], the SKAP-25 + SMBT mixture (7.1:1 by weight) exhibited high protective properties against copper in an aqueous solution of $3.5 \% \mathrm{NaCl}$. In the present work the study of this composition was continued not only by electrochemical method (taking polarization curves), but also in corrosion tests.

Figure 4 shows the anodic polarization curves of the MNZH5-1 alloy in a borate buffer solution of $\mathrm{pH} 7.4$ containing $0.01 \mathrm{~mol} / \mathrm{L} \mathrm{NaCl}$ and different concentrations of SKAP- $25+$ SMBT mixture (7.1:1). If we compare this mixture with its main substance, we can see that much lower $C_{\text {in }}$ is needed to reduce the $i_{\mathrm{p}}$ of the second peak. Thus, as early as $0.0015 \mathrm{~g} / \mathrm{L}$ SKAP-25+SMBT suppresses anodic dissolution in the region of the first peak potentials and increases $E_{\mathrm{pt}}$ by $0.03 \mathrm{~V}$. With further increase in $C_{\text {in }}$ the second peak of anodic dissolution is suppressed and $E_{\mathrm{pt}}$ increases up to $1.02 \mathrm{~V}$ at $C_{\mathrm{in}}=0.0769 \mathrm{~g} / \mathrm{L}$.

Analyzing the results of electrochemical studies, it can be noted that there is a mutual strengthening of protective properties between SKAP-25 and SMBT in their mixture. It is of interest to evaluate the protective capacity of SKAP-25, as well as its composition with SMBT in relation to copper and alloy MNZh5-1 in corrosion tests in an aqueous solution of 
chlorides. These tests were carried out on plates of copper and alloy in $0.01 \mathrm{M}$ and $3.5 \%$ aqueous solution of $\mathrm{NaCl}$.

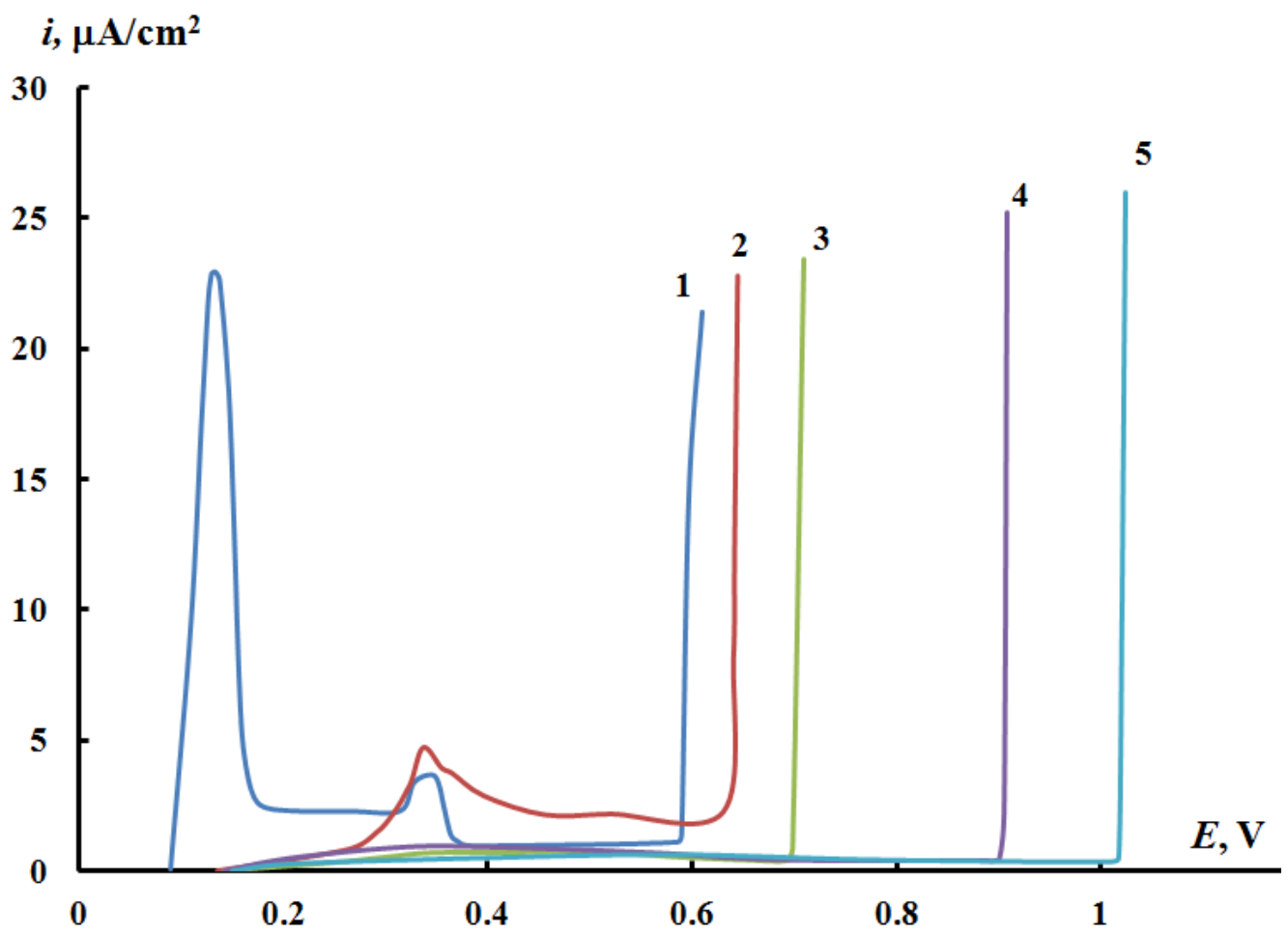

Figure 4. Anodic polarization curves of MNZh5-1 alloy in borate buffer solution $\mathrm{pH} 7.4$ containing $0.01 \mathrm{M} \mathrm{NaCl}$ (1) with addition of SKAP-25+SMBT mixture (7:1) (in g/L): 2 $0.012,3-0.025,4-0.046,5-0.077$.

Consider the inhibitory properties of dicarboxylate additives for copper protection in a solution containing $0.01 \mathrm{M} \mathrm{NaCl}$ (Figure 5a). Already with the introduction of SKAP-25 in an amount of $0.0337 \mathrm{~g} / \mathrm{L}$ the protective effect $Z=58 \%$ is observed and increases with increasing $C_{\text {in }}$ to $0.674 \mathrm{~g} / \mathrm{L}$, reaching $100 \%$. Using SMBT, $0.283 \mathrm{~g} / \mathrm{L} \mathrm{CI}$ is required to achieve complete copper protection. Using SKAP-25+SMBT as the CI mixture, at $C_{\text {in }}=$ $0.1537 \mathrm{~g} / \mathrm{L}$ the protective effect reaches $98.3 \%$, and fully protects copper at $C_{\text {in }}=0.461 \mathrm{~g} / \mathrm{L}$, which contains $0.057 \mathrm{~g} / \mathrm{L}$ SMBT, which is almost 5 times less than using SMBT itself. Thus, smaller amounts of SMBT can be used to protect copper by diluting it with SKAP-25. This avoids the substantial alkalization of the medium that occurs when using SMBT itself: the $\mathrm{pH}$ of the solution containing $0.1 \mathrm{~g} / \mathrm{L}$ of this $\mathrm{CI}$ is 9.5 .

Since the composition of SKAP-25 with SMBT provided high protection of copper against corrosion in $0.01 \mathrm{M} \mathrm{NaCl}$, tests were continued in a more aggressive aqueous solution containing 3.5\% NaCl (Figure 5b). Under these conditions at $0.506 \mathrm{~g} / \mathrm{L} \mathrm{SKAP-25}$ $Z=40 \%$ and increases to $55 \%$ at $C_{\text {in }}=1.685 \mathrm{~g} / \mathrm{L}$. Under such severe conditions full protection of copper was achieved only by introduction of SKAP-25+SMBT (7.1:1) at $C_{\text {in }}=$ $1.537 \mathrm{~g} / \mathrm{L}$. 

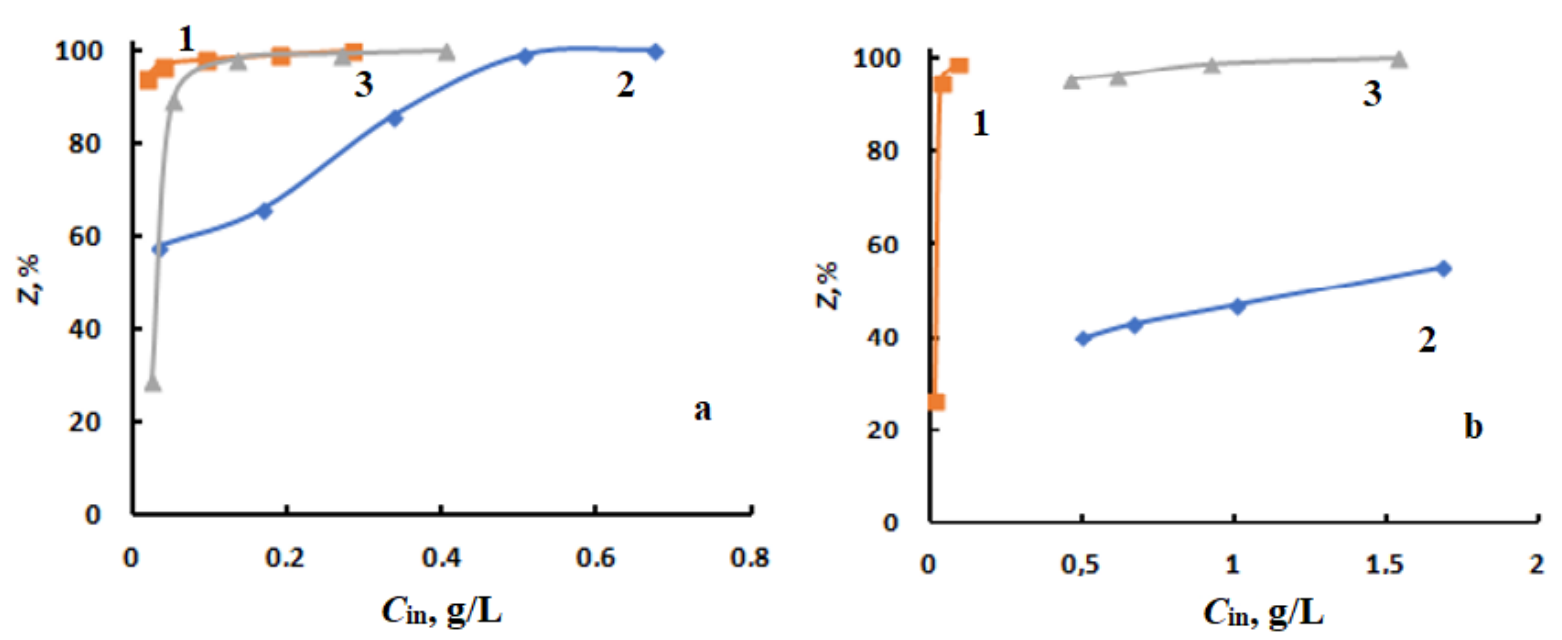

Figure 5. Dependence of the degree of protection of copper in $0.01 \mathrm{M}$ (a) $\mathrm{NaCl}$ and $3.5 \%$ $\mathrm{NaCl}$ solution (b) on the concentration of sodium salts of KAP-25 (curve 2), 2-MBT (curve 1) and their mixture (curve 3 ).

In the case of the MNZh5-1 alloy in a $0.01 \mathrm{M}$ solution (Figure 6a), the use of SKAP25 provides $Z=74 \%$ at $C_{\text {in }}=0.169 \mathrm{~g} / \mathrm{L}$ and increases to $87 \%$ at $C_{\text {in }}=1.011 \mathrm{~g} / \mathrm{L}$. When a mixture of SKAP-25+SMBT (7.1:1) is used, a higher protection efficiency is observed. Already at $C_{\text {in }}=0.30 \mathrm{~g} / \mathrm{L} Z>95 \%$, and at $C_{\text {in }}=0.6 \mathrm{~g} / \mathrm{L}$ full protection of the alloy is achieved.

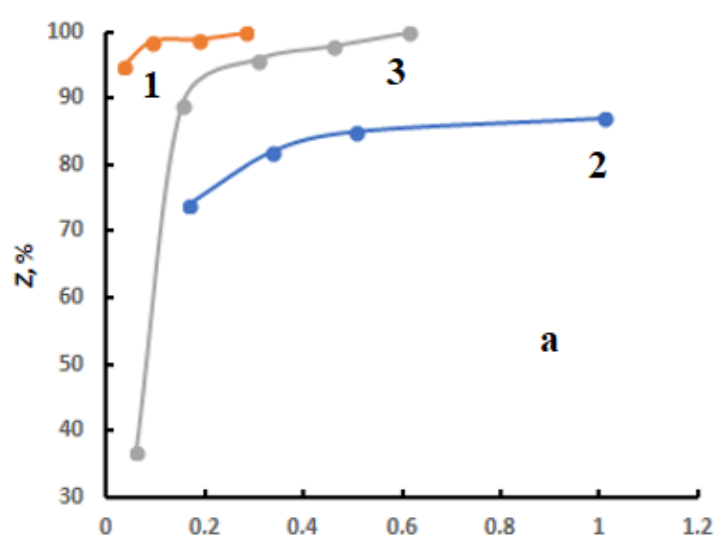

$C_{\text {in, }}, \mathbf{g} / \mathrm{L}$

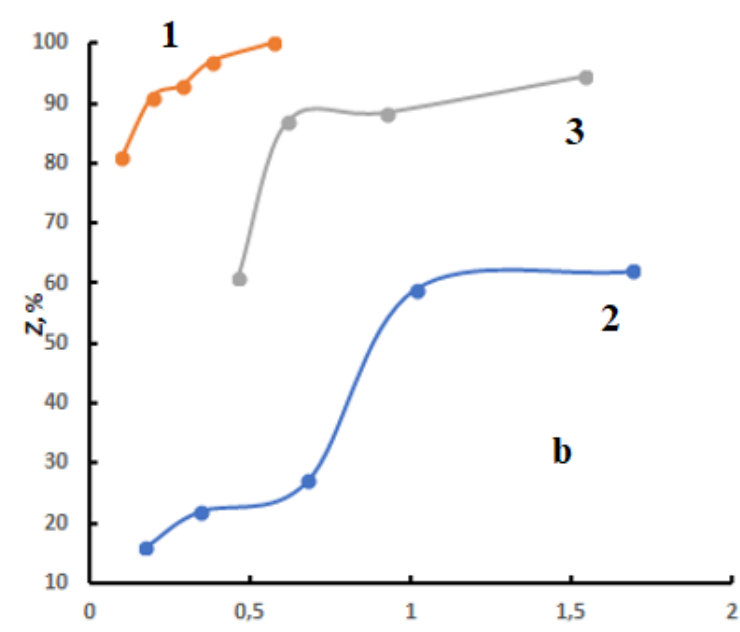

$C_{\text {in, }} \mathbf{g} / \mathrm{L}$

Figure 6. Dependence of the degree of protection of MNZh5-1 alloy in $0.01 \mathrm{M}$ (a) $\mathrm{NaCl}$ and $3.5 \% \mathrm{NaCl}$ solution (b) on the concentration of sodium salts of KAP-25 (curve 2), 2-MBT (curve 1) and their mixture (curve 3).

In a more aggressive solution of $3.5 \% \mathrm{NaCl}$ (Figure 6b) full protection of the alloy is observed only when using SMBT with $C_{\text {in }}=0.567 \mathrm{~g} / \mathrm{L}$. SKAP- 25 itself is little effective in this solution: even at $C_{\mathrm{in}}=1.685 \mathrm{~g} / \mathrm{L}, Z=62 \%$, but using the composition SKAP-25 + SMBT (7.1:1), it was possible to significantly increase $Z$ to $94.5 \%$. 


\section{Conclusions}

1. Adsorption of sodium salts of itaconic and succinic acids and, probably, its mixture of alkenyl derivatives SKAP-25 on the oxidized surface of copper and alloy MNZh5-1 in borate buffer solution is of chemical nature.

2. SKAP-25 anions and its composition with SMBT can passivate copper and its alloy MNZh5-1 in borate buffer containing $0.01 \mathrm{M} \mathrm{NaCl}$ and prevent their local depassivation by chlorides up to the potentials of oxygen release on the electrode.

3. Corrosion tests of copper and alloy in $0.01 \mathrm{M} \mathrm{NaCl}$ and $3.5 \% \mathrm{NaCl}$ solutions showed that it is possible to increase the protective properties of SKAP-25 using it in the composition with SMBT (at their ratio of 7.1:1). Although it lacks synergistic protective action, it is capable of suppressing copper corrosion without significantly increasing the $\mathrm{pH}$ of the solution at $C_{\text {in }}=0.461 \mathrm{~g} / \mathrm{L}$ in $0.01 \mathrm{M} \mathrm{NaCl}$ and $1.537 \mathrm{~g} / \mathrm{L}$ in $3.5 \% \mathrm{NaCl}$. This mixed CI is capable of completely suppressing corrosion of the alloy MNZh5-1 in $0.01 \mathrm{M} \mathrm{NaCl}$ solution at $C_{\text {in }}=0.6 \mathrm{~g} / \mathrm{L}$ and providing a high degree of corrosion protection $(Z=94.5 \%)$ in $3.5 \% \mathrm{NaCl}$ at $C_{\text {in }}=1.685 \mathrm{~g} / \mathrm{L}$.

\section{References}

1. N. Kovačević, I. Milošev and A. Kokalj, How relevant is the adsorption bonding of imidazoles and triazoles for their corrosion inhibition of copper, Corros. Sci., 2017, 124, 25-34. doi: $10.1016 /$ j.corsci.2017.04.021

2. N.K. Allam, A.A. Nazeer and E.A. Ashour, A review of the effects of benzotriazole on the corrosion of copper and copper alloys in clean and polluted environments, J. Appl. Electrochem., 2009, 39, 961-969. doi: 10.1007/s10800-009-9779-4

3. M. Finšgar and I. Milošev, Inhibition of copper corrosion by 1,2,3-benzotriazole: A review, Corros. Sci., 2010, 52, 2737-2749. doi: 10.1016/j.corsci.2010.05.002

4. M. Petrović Mihajlović and M.M. Antonijević, Copper Corrosion Inhibitors. Period 2008-2014. A Review, Int. J. Electrochem. Sci., 2015, 10, 1027-1053.

5. S.M. Milić, M.M. Antonijević and M.B. Petrović, Films formed on copper surface in chloride media in the presence of azoles, Corros. Sci., 2009, 51, 1228-1237. doi: 10.1016/j.corsci.2009.03.026

6. Yu.I. Kuznetsov, Triazoles as a class of multifunctional corrosion inhibitors. A review. Part I. 1,2,3-Benzotriazole and its derivatives. Copper, zinc and their alloys, Int. J. Corros. Scale Inhib., 2018, 7, no. 3, 271-307. doi: 10.17675/2305-6894-2018-7-3-1

7. H. Huang, Z. Wang, Y. Gong, F. Gao, Z. Luo, S. Zhang and H. Li, Water soluble corrosion inhibitors for copper in 3.5wt\% sodium chloride solution, Corros. Sci., 2017, 123, 339-350. doi: 10.1016/j.corsci.2017.05.009

8. H. Otmacic Curkovic, E. Stupnisek-Lisac and H. Takenouti, The influence of $\mathrm{pH}$ value on the efficiency of imidazole based corrosion inhibitors of copper, Corros. Sci., 2010, 52, no. 2, 398-405. doi: 10.1016/j.corsci.2009.09.026 
9. E. Rocca, G. Bertrand, C. Rapin and J.C. Labrune, Inhibition of copper aqueous corrosion by non-toxic linear sodium heptanoate: mechanism and ECAFM study, $J$. Electroanal. Chem., 2001, 503, 133-140. doi: 10.1016/S0022-0728(01)00384-9

10. M. Ohsawa and W. Suetaka, Spectro-electrochemical studies of the corrosion inhibition of copper by mercaptobenzothiazole, Corros. Sci., 1979, 19, no. 10, 709-722. doi: 10.1016/S0010-938X(79)80069-4

11. G. Rajkumar and M.G. Sethuraman, Corrosion protection ability of self-assembled monolayer of 3-amino-5-mercapto-1,2,4-triazole on copper electrode, Thin Solid Films, 2014, 562, 32-36. doi: 10.1016/j.tsf.2014.03.074

12. G. Chan-Rosado and M.A. Pech-Canul, Influence of native oxide film age on the passivation of carbon steel in neutral aqueous solutions with a dicarboxylic acid, Corros. Sci., 2019, 153, 19-31. doi: 10.1016/j.corsci.2019.03.033

13. F. Capriolim, A. Martinellim, V. DiCastrom and F. Decker, Effect of various terminal groups on long-term protective properties of aromatic SAMs on copper in acidic environment, J. Electroanal. Chem., 2013, 693, 86-94. doi: 10.1016/j.jelechem.2013.01.025

14. M.O. Agafonkina, Yu.I. Kuznetsov and N.P. Andreeva, Inhibitor Properties of Carboxylates and Their Adsorption on Copper from Aqueous Solutions, Russ. J. Phys. Chem. A, 2015, 89, no. 6, 1070-1076. doi: 10.1134/S0036024415060023

15. E. Abelev, D. Starosvetsky and Y. Ein-Eli, Enhanced Copper Surface Protection in Aqueous Solutions Containing Short-Chain Alkanoic Acid Potassium Salts, Langmuir, 2007, 23, 11281-11288. doi: 10.1021/la701434e

16. G.T. Hefter, N.A. North and S.H. Tan, Organic corrosion inhibitors in neutral solutions. Part 1. Inhibition of steel, copper and aluminum by straight chain carboxylates, Corrosion, 1997, 53, 657-667. doi: 10.5006/1.3290298

17. K. Aramaki and T. Shimura, Self-assembled monolayers of carboxylate ions on passivated iron for preventing passive film breakdown, Corros. Sci., 2004, 46, 313-328. doi: $10.1016 /$ S0010-938X(03)00156-2

18. U. Rammelt, S. Köhler and G. Reinhard, Electrochemical characterization of the ability of dicarboxylic acid salts to the corrosion inhibition of mild steel in aqueous solutions, Corros. Sci., 2011, 53, 3515-3520. doi: 10.1016/j.corsci.2011.06.023

19. D. Lahem, M. Poelman, F. Atmani and M.G. Olivier, Synergistic improvement of inhibitive activity of dicarboxylates in preventing mild steel corrosion in neutral aqueous solutions, Corros. Eng., Sci. Technol., 2012, 47, 463-471. doi: 10.1179/1743278212Y.0000000030

20. G. Chan-Rosado and M.A. Pech-Canul, Influence of native oxide film age on the passivation of carbon steel in neutral aqueous solutions with a dicarboxylic acid, Corros. Sci., 2019, 153, 19-31. doi: 10.1016/j.corsci.2019.03.033

21. G. Žerjav and I. Milošev, Carboxylic Acids as Corrosion Inhibitors for $\mathrm{Cu}, \mathrm{Zn}$ and Brasses in Simulated Urban Rain, Int. J. Electrochem. Sci., 2014, no. 9, 2696-2715. 
22. A.D. Mercer, The properties of carboxilates as corrosion inhibitors for steel and other metals in neutral aqueous solutions, In Proceeding of the 5th Europ. Symp. on Corros. Inhib., Ferrara (Italy), 1980, 2, 563-581.

23. Yu.I. Kuznetsov, I.A. Kuznetsov and D.B. Vershok, Copper corrosion protection in neutral media by dicarboxylic acid salts, Int. J. Corros. Scale Inhib., 2019, 8, no. 4, 1022-1034. doi: $10.17675 / 2305-6894-2019-8-4-13$

24. TU 2499-080-05015207-2003, An additive to anticorrosion formulations to prevent rusting of metal surfaces (in Russian).

25. GOST 492-2006, Nickel, nickel and copper-nickel mechanically worked alloys. Brands (in Russian).

26. R.M. Azzam and N.M. Bashara, Ellipsometry and Polarized Light, North-Holland, Amsterdam, 1977, $529 \mathrm{p}$.

27. P. Silva-Bermudez, S.E. Rodil and S. Muhl, Albumin adsorption on oxide thin films studied by spectroscopic ellipsometry, Appl. Surf. Sci., 2011, 258, 1711-1718. doi: $\underline{\text { 10.1016/j.apsusc.2011.10.020 }}$

28. L. Wang, C. Zhao, M.H.G. Duits, F. Mugele and I. Siretanu, Detection of ion adsorption at solid-liquid interfaces using internal reflection ellipsometry, Sens. Actuators, B, 2015, 210, 649-655. doi: 10.1016/j.snb.2014.12.127

29. M.O. Agafonkina, N.P. Andreeva, Yu.I. Kuznetsov and S.F. Timashev, Substituted Benzotriazoles as Inhibitors of Copper Corrosion in Borate Buffer Solutions, Russ. J. Phys. Chem. A, 2017, 91, no. 8, 1414-1421. doi: 10.1134/S0036024417080027

30. M.O. Agafonkina, I.A. Kuznetsov, N.P. Andreeva and Yu.I. Kuznetsov, Copper protection with sodium salts of lower dicarboxylic acids in neutral aqueous solution, Int. J. Corros. Scale Inhib., 2020, 9, no. 3, 1000-1013. doi: 10.17675/2305-6894-2020-9-3$\underline{13}$

31. M.O. Agafonkina, I.A. Kuznetsov, Yu.I. Kuznetsov, O.Yu. Grafov and N.P. Andreeva, Corrosion inhibition of MNZh alloy with sodium salts of lower dicarboxylic acids in neutral aqueous solution, Int. J. Corros. Scale Inhib., 2021, 10, no. 1, 349-367. doi: $\underline{10.17675 / 2305-6894-2020-10-1-20}$ 